\title{
Health returns to cognitive capital in the British 1946 birth cohort
}

\author{
Marcus Richards ${ }^{1}$, Alison Stephen ${ }^{2}$ and Gita Mishra ${ }^{1}$ \\ ${ }^{1}$ MRC Unit for Lifelong Health and Ageing, London UK \\ ${ }^{2}$ MRC Human Nutrition Research, Cambridge, UK \\ m.richards@nshd.mrc.ac.uk
}

Received April 2010 Revised June 2010)

\begin{abstract}
The association between education and health has long been discussed; but more recently the question of whether this association is accounted for by cognitive capital has received considerable attention, including in the British birth cohorts. Following work in the British 1970 cohort, we investigated childhood cognition in relation to six health outcomes in mid-life, linked to risk of cardiovascular disease in the British 1946 cohort. These outcomes were smoking, physical exercise, healthy dietary choice, obesity, hypertension and non insulin-dependent diabetes, at or by age 53 years. Childhood cognition was associated with all of these outcomes, although for all except exercise and healthy diet this was fully mediated by educational attainment and partially so by adult socio-economic attainment. Cognitive capital plays a role in the accumulation of risk for chronic physical disease in mid-life, but it is not a sufficient determinant of this risk and does not account for the association between education and health outcomes related to this risk.
\end{abstract}

\section{Introduction}

It has long been known that educational attainment is associated with health and survival. Schooling directly builds human capital including expertise, personal control and social support (Ross and Mirowsky, 1999) and structures other components of socio-economic status SES, such as occupational status and income (O'Rand 2001; Mirowsky and Ross 2003), all of which promote and protect health. Education may also mediate the effects of early life adversity, or material and sociocultural resources from the family, on mental health (Blane, 2003).

These processes are also thought to be generated by cognitive capital'; indeed, cognitive ability predicts educational attainment (Deary et al 2007), to the extent that it has been argued to be the "fundamental" cause of these educational effects on health (Gottfredson 2004). However, cognitive capital and education are not simply interchangeable determinants in this respect. Cognitive ability is almost certainly a more sensitive marker of underlying physiological processes that regulate health, than educational attainment. For example the autonomic, immune and major endocrine systems, all target neural networks that support higher mental function; thus early cognition may act as an indicator of "system integrity" (Whalley and Deary 2001). It is also substantially genetically determined (Plomin 1999), in ways that are pleiotropic for physical health systems (Deary et al 2009). Conversely, education is capable of influencing health in ways that are not accounted 
for by intelligence quotient IQ and can itself boost cognitive skills independently of prior ability (Snow and Yallow 1982; Hernstein and Murray 1994; Richards and Sacker 2003; Hatch et al 2007a). Schooling socialises the individual for success in adulthood by developing 'non-cognitive' or 'soft' skills such as self-regulation (Duckworth et al 2009, Duckworth and Schoon 2010), although in the current educational environment of assessment and accountability, these broader aspects of learning are in danger of becoming de-emphasised in favour of academic curricular achievement (Duckworth and Schoon, 2010). Educational attainment also provides a readily-identifiable signal (Rosenbaum et al 1990) or credential (Collins 1979) for selection into the labour market. Social position thus achieved in turn, enables access to the collective resources of a community, including those based on its aggregate cognitive capital over and above any returns expected to individual ability (Link and Phelan 2008). Thus cognition may be an important marker of biological pathways to health, whereas education may better represent social pathways. On this basis childhood IQ may be independently associated with health-related outcomes that closely reflect neural function, such as the degenerative dementias and mental health, whereas education and SES may be stronger determinants of chronic physical diseases of ageing (Richards et al 2009). If so, then a 'fundamental cause' approach is unlikely to represent the complex dynamic interplay between cognition, education and adult socio-economic achievement in their determination of health and health inequalities.

Childhood cognition has been investigated as a predictor of a range of health-related outcomes in the adult British birth cohorts (Tables 1 and 2). It can be seen that childhood cognition is associated with a wide range of outcomes, but that for most health behaviours and for cardiovascular risk factors, education or adult SES act as mediating links. Exceptions were seen in the direct associations between childhood cognition and risky alcohol intake, symptoms of anxiety and depression and markers of physiological function ( $\mathrm{FEV}_{1}$ [forced expiratory volume in one second], timing of the natural menopause and cortisol activity). 
Table 1. Published studies on health behaviours in relation to childhood cognition in the adult British birth cohorts

$\begin{array}{llll}\text { Outcome } & 1946 \text { cohort (age } 53 \text { years) } & 1958 \text { cohort (age 33-45 years) } & 1970 \text { cohort (age 30-34 years) }\end{array}$

\begin{tabular}{|c|c|c|c|}
\hline Smoking & ----- & $\begin{array}{l}\text { Inversely associated; mediated by } \\
\text { education and maternal age } \\
\text { (Gale et al 2009) }\end{array}$ & $\begin{array}{l}\text { Inversely associated; mediated by } \\
\text { education and maternal age } \\
\text { (Gale et al 2009a) }\end{array}$ \\
\hline & & & $\begin{array}{l}\text { Inversely associated; mediated by } \\
\text { SES (Batty et al 2007a) }\end{array}$ \\
\hline Alcohol & $\begin{array}{l}\text { Positively and independently } \\
\text { associated with being CAGE } \\
\text { positive (Hatch et al 2007b) }\end{array}$ & $\begin{array}{l}\text { Inversely associated with non-drinking } \\
\text { and binge-drinking; mediated by SES } \\
\text { (Jefferis et al 2008) }\end{array}$ & $\begin{array}{l}\text { Positively and independently } \\
\text { associated with intake and being } \\
\text { CAGE positive (Batty et al 2008) }\end{array}$ \\
\hline Exercise & ----- & ----- & $\begin{array}{l}\text { Positively associated; mediated by } \\
\text { SES (Batty et al } 2007 \mathrm{~b} \text { ) although } \\
\text { independent for intense exercise }\end{array}$ \\
\hline Dietary choice & ----- & ---- & $\begin{array}{l}\text { Positively associated with healthy } \\
\text { intake; part-mediated by SES } \\
\text { (Batty et al 2007b) }\end{array}$ \\
\hline & & & $\begin{array}{l}\text { Positively and independently associated } \\
\text { with vegetarian diet } \\
\text { (Gale et al 2007) }\end{array}$ \\
\hline
\end{tabular}


Table 2. Published studies on mortality and health-related outcomes in relation to childhood cognition in the adult British birth cohorts

\section{Outcome}

1946 cohort (age 53-60 years)

1958 cohort (age 33-46 years)

1970 cohort (age 30 years)
Mortality

Inversely associated with mortality up to age 60 in

men; mediated by SES

(Kuh et al 2004 ${ }^{1}$ )

Hypertension

Inversely associated; mediated by education and SES

(Richards et al 2009)

Obesity

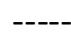

Diabetes

Metabolic

syndrome

(ATPIII criteria)
Not associated with non-fasting glycosolated haemoglobinal

(Richards et al 2009)

Inversely associated; mediated

by education and SES

(Richards et al 2009)
Inversely associated with mortality mortality to age 46; part-mediated

by SES (Jokela et al 2009)

Inversely associated; part-mediated by education (Power et al 2010)

Inversely associated; mediated by education and diet (Chandola et al 2006²)

Inversely associated; mediated by education and health behaviours (Power et al 2010)

Inversely associated; analyses not adjusted for education or adult SES

(Olsson et al 2008)
Inversely associated; mediated by education (Batty et al 2007a)

Inversely associated; mediated by education (Batty et al 2007a) 
Table 2 (continued)

\section{Outcome}

1946 cohort

Inversely and independently

associated in women

(Hatch et al 2007b)

anxiety and

depression

Lung function

$\left(\mathrm{FEV}_{1}\right)$

Positively and independently

associated (Richards et al

2005)

Menopause

Timing

Endocrine function

(cortisol)
Positively and independently associated (Richards et al $1999^{3}$ )
1958 cohort

Inversely and independently associated (Gale et al 2009b)

Inversely and independently associated (Gale et al 2009b)

\section{0 cohort}

Positively associated with level

(mediated by education in males) and

change (mediated by education)

(Power et al 2008)

\footnotetext{
${ }^{1}$ See also Kuh et al 2009

${ }^{2}$ Obesity assessed at ages 16, 23, 33 and 42 years

${ }^{3}$ See also Kuh et al 2005
} 
Some discrepancies can be observed in the findings for alcohol and diabetes. Regarding the former, the study of Jefferis et al (2008), using the 1958 cohort, stands out as being the only one showing an inverse association between childhood cognition and potentially harmful intake; but this was the only study to capture the pattern of binge drinking; and this association was in any case mediated by SES, unlike the positive associations in the 1946 and 1958 cohorts. Cross-cohort comparisons for diabetes are more difficult, because the 1946 cohort study used a biomarker rather than clinical diagnosis; the 1958 cohort study did not control for education or adult SES; and the 1970 cohort study was inadequately powered for this outcome.

The aim of the present study was to fill several of the gaps in Tables 1 and 2 by testing childhood cognition in the 1946 cohort in relation to risk of cardiovascular disease, as indicated by self-reported smoking, physical exercise, dietary choice and measured hypertension and obesity. Findings for hypertension were briefly reported in the 1946 cohort at age 53 (Richards et al 2009) and are revisited in greater detail here and are supplemented by a measured obesity outcome. Our working hypothesis, based on studies summarised in Tables 1 and 2, was that associations between childhood cognition and these outcomes are mediated by educational attainment, which is part-determined by cognitive ability yet provides unique influences on disease risk. Thus we hypothesised that cognition is an important but not sufficient cause of cardiovascular disease risk.

\section{Method}

\section{The 1946 birth cohort}

The Medical Research Council National Survey of Health and Development (NSHD, henceforth the 1946 cohort; Wadsworth et al 2006) was originally established to investigate the cost of childbirth and the quality of associated care in the immediate post-war years. A sample of 5,362 , comprising all single births within marriage to families of nonmanual and agricultural occupation and a random one in four sample of single births within marriage to families of manual occupation, was recruited from all births registered in one week of March 1946 in England, Wales and Scotland. Follow-ups have been completed 21 times, with the major data-sweeps in adulthood conducted at ages 26, 36, 43 and 53 years, when sample size during the latter follow-up was 3,050 . At this age the cohort was shown to be a representative sample, in most respects, of the UK population singly born within marriage in the immediate post-war era. Exceptions were an over-representation among those not interviewed of social disadvantage, medical vulnerability and relatively poor cognitive development.

\section{Health-related outcomes Lifetime smoking}

Lifetime cigarette smoking was classified as 'predominantly no' or 'predominantly yes', based on information at ages 20, 25, 31, 36, 43 and 53 years. From age 36 onwards this information was collected by trained research nurses during home interviews; at the earlier ages this was based on postal questionnaires. At each age, smoking was dichotomised into yes or no regardless of quantity; those classified as 'predominantly no' were nonsmokers for at least three data collections; those classified as 'predominantly yes' were smokers for at least four data collections.

\section{Physical exercise}

At 53 years, survey members were asked if, in the past four weeks, they had taken part in any sports or vigorous leisure activities, or performed any exercises in their spare time (not including travelling to and from work). The outcome was simply classified as yes or no.

\section{Dietary choice}

Dietary intake was assessed by five-day diary at age 43 years (Price et al 1995). All food and drinks consumed both at and away from home were recorded in the diaries, including brand names of food products, food preparation methods and recipes used. Participants were asked to record the amount eaten in household measures, with guidance notes and photographs provided in the diary to assist in estimating portion size (Prynne et al 2005). From this information, an overall score representing level of healthy food choice was derived, by summing scores for four separate criteria: 1 . consumption of breakfast (no/some/all days); 2. type of milk (from whole only to skimmed only); 3 . type of bread (from white only to wholemeal only); 4. number of daily portions of 
fruit and vegetables. The total score was subject to a median split to represent low versus high (energy dense/nutrient poor versus healthier) dietary choice. A measure of total energy derived from fat was also available from this source.

\section{Hypertension at 53 years}

Hypertension at age 53 years was defined as a measured blood pressure of $130 / 85 \mathrm{mmHg}$ or more, on second reading at this age, or use of antihypertensive medication. Blood pressure was measured by trained nurses using calibrated OMRON 705 CP sphygmomanometers.

\section{Obesity at 53 years}

Presence or absence of obesity at age 53 years was based on height and weight, measured by trained nurses according to standard protocol. Obesity was defined as a body mass index (BMI) of $30 \mathrm{~kg} / \mathrm{m}^{2}$ or more. Abdominal circumference and waist-hip ratio were also obtained at this time, according to standard protocol.

\section{Diabetes by age 53 years}

Presence or absence of Type 2 (non-insulindependent) diabetes by age 53 years was based on self-report and information about medication. Diabetes diagnosed under age of 20 years was assumed to be Type 1 and any woman, whose diabetes was diagnosed within a year of the birth of one of her children, was reviewed for possible gestational diabetes.

\section{Childhood cognition}

Four tests devised by the National Foundation for Educational Research (NFER) were used at age 11 years; 1 . General cognitive ability, assessed by a verbal and non-verbal test, where participants were asked to select an appropriate word or shape to complete 80 different series, yielding scores for Verbal Intelligence and Non-Verbal Ability; 2. Word Reading (ability to read and pronounce 50 words); 3. Vocabulary (ability to explain the meaning of the same 50 words); 4. An Arithmetic Test, comprising 50 addition, multiplication, subtraction and division sums. To derive a global measure of cognitive ability at this age, these four separate scores were standardised to a mean of 0 and a standard deviation (SD) of 1 ; these scores were then summed and re-standardised. These standardised scores were used for regression analyses, whereas the raw scores were used for univariate analyses and for descriptive purposes.

\section{Potential confounders}

Following work on the 1970 cohort we selected the following potential confounders:

\section{Occupational social class of origin}

Socio-economic status (SES) of origin was represented by father's social class at age 11 or, if unknown, at age 4 or 15 years. This was classified as professional managerial intermediate, skilled non-manual skilled manual semi-skilled manual or unskilled, according to the UK Registrar General's Classification of Occupations (Office of Population Censuses and Surveys 1970).

\section{Mother's education}

Mother's education was dichotomised to primary school only and secondary school or any training/qualifications.

\section{Educational attainment}

The highest educational qualification attained by 26 years was classified as no qualification, below ordinary secondary qualifications, ordinary secondary qualifications (' $O$ ' levels and their training equivalents), advanced secondary education (' $A$ ' levels and their equivalents), or higher education (degree level or equivalent).

\section{Occupational social class at age $\mathbf{5 3}$ years}

Own occupational social class at 53 years, or earlier if this was unknown, was classified according to the Registrar General (as for social class of origin).

\section{Income at 53 years}

Net household income at age 53 years was defined as the total of own and partner's net earnings, any state benefits and any other sources of income including pensions and interest and contributions from other members of the household. This total was grouped into seven levels with roughly equal numbers of survey members in each.

\section{Statistical analysis}

Logistic regression was used to test the association between childhood cognition and the health-related outcomes. Following work based on the 1970 cohort, unadjusted odds ratios were initially obtained, then adjusted in turn for sex and each of the above potential confounders, then for all potential confounders simultaneously. All multilevel potential confounders (i.e. all except sex and mother's education) were entered into the analyses as categorical variables. 


\section{Results}

For each outcome, those with missing data had significantly lower childhood cognition than those with this information ( $p<0.001$ for all outcomes except for diabetes, where $p=0.001$ ).

Table 3 shows means for the raw childhood cognition score for presence and absence of each outcome. As expected, those who were predominantly smokers and who had measured hypertension or obesity, had significantly lower cognitive scores than those who were predominantly non-smokers and who did not have hypertension or obesity; those who engaged in physical exercise at 53 years and chose a healthy diet at 43 years, had significantly higher childhood cognitive scores.

Table 3. Means and standard deviations (SD) for childhood cognition against the outcomes

N Mean (SD)

p

Lifetime smoking to $53 y$

Mostly no

Mostly yes

Any exercise at $53 y$

No

Yes

Healthy diet at $43 y$

No

Yes

Hypertension at 53y

No

Yes

Obesity at $53 y$

No

Yes

Diabetes by 53 years

No

Yes $\begin{array}{lll}1332 & 146.1 \quad(37.5)\end{array}$

$\begin{array}{llll}777 & 134.2 & (40.9)\end{array}$

$<0.001$

$1070 \quad 131.2 \quad(40.1)$

$1115 \quad 151.3 \quad(35.8)$

$<0.001$

$\begin{array}{lll}752 & 136.4 & (39.1)\end{array}$

$\begin{array}{llll}741 & 154.1 & (35.0)\end{array}$

$<0.001$

$1062 \quad 144.3 \quad(38.2)$

$\begin{array}{llll}1082 & 138.4 & (40.0) & 0.001\end{array}$

$\begin{array}{lll}1636 & 143.3 \quad(38.5)\end{array}$

$\begin{array}{llll}523 & 135.4 & (41.0) \quad<0.001\end{array}$
Table 4 shows associations between the five outcomes and the six potential confounders. Females were significantly more likely to be predominantly non-smokers, to choose a healthy diet and to be normotensive; however, they were less likely to engage in exercise and more likely to be obese at 53 years. Non-manual social class (of origin and own in mid-life), advanced education and higher income were mostly significantly associated with lower cardiovascular risk in regard to each of the six outcomes. The single exception was the association between income and hypertension, which was not significant at the $5 \%$ level. 
Table 4. Descriptive statistics for outcomes against each covariate

\begin{tabular}{|c|c|c|c|c|c|c|c|c|c|c|c|c|}
\hline & \multicolumn{2}{|c|}{ Smoking } & \multicolumn{2}{|c|}{ Exercise } & \multicolumn{2}{|c|}{ Healthy diet } & \multicolumn{2}{|c|}{ Hypertension } & \multicolumn{2}{|c|}{ Obesity } & \multicolumn{2}{|c|}{ Diabetes } \\
\hline & No & Yes & No & Yes & No & Yes & No & Yes & No & Yes & No & Yes \\
\hline Gender (\% female) & 51.9 & 46.3 & 51.8 & 47.5 & 43.6 & 57.1 & 56.6 & 42.1 & 48.2 & 53.2 & 49.6 & 51.5 \\
\hline $\begin{array}{l}\text { Father's social class } \\
\text { (\% non-manual) }\end{array}$ & 46.0 & 34.5 & 33.1 & 50.0 & 34.6 & 54.9 & 46.8 & 37.2 & 44.5 & 32.1 & 42.2 & 25.0 \\
\hline $\begin{array}{l}\text { Mother's education } \\
\text { (\% with qualifications) }\end{array}$ & 40.7 & 32.3 & 29.3 & 45.9 & 32.0 & 47.5 & 40.4 & 35.6 & 39.6 & 31.7 & 38.2 & 25.0 \\
\hline $\begin{array}{l}\text { Education } \\
\left(\% \text { advanced }^{1}\right)\end{array}$ & 42.0 & 25.2 & 23.4 & 47.9 & 27.9 & 49.0 & 38.1 & 33.5 & 38.1 & 28.3 & 36.3 & 19.1 \\
\hline $\begin{array}{l}\text { Mid-life social class } \\
\text { (\% non-manual) }\end{array}$ & 73.5 & 54.3 & 55.4 & 76.9 & 58.4 & 77.5 & 70.2 & 62.3 & 68.7 & 58.9 & 66.8 & 51.5 \\
\hline $\begin{array}{l}\text { Income at } 53 \text { years } \\
\text { (\% higher) }\end{array}$ & 48.0 & 29.2 & 30.3 & 51.1 & 33.2 & 48.9 & 42.7 & 39.6 & 42.5 & 36.7 & 41.5 & 23.5 \\
\hline
\end{tabular}

All comparisons significant at $5 \%$ except for hypertension in relation to earnings and gender in relation to diabetes.

${ }^{1}$ ' $A$ ' level qualification or higher.

Tables 5 and 6 summarise the associations between childhood cognition and the six outcomes, represented as odds ratios (OR) per 1 SD increase in cognitive score. Childhood cognition was significantly associated with all outcomes at the $5 \%$ level.
However, only two of these associations, physical exercise and health diet, were still significant after full adjustment for all the covariates. 
Table 5. Odds ratios and 95\% confidence intervals representing the effect of a 1 SD increase in childhood cognitive score on engagement in three mid-life health behaviours

\section{Predominantly a lifetime} smoker

\section{Unadjusted}

Gender

Parental SES

Own education

Mid-life social class

Mid-life income

All
$0.74(0.68,0.81) p<0.001$

$0.74(0.68,0.81) p<0.001$

$0.79(0.71,0.87) p<0.001$

$0.98(0.87,1.10) p=0.70$

$0.87(0.79,0.97) p=0.01$

$0.82(0.75,0.91) p<0.001$

$1.08(0.95,1.22) p=0.22$
Physical exercise at 53 years

$\begin{array}{ll}1.74(1.59,1.91) \mathrm{p}<0.001 & 1.68(1.50,1.88) \mathrm{p}<0.001 \\ 1.75(1.60,1.92) \mathrm{p}<0.001 & 1.69(1.51,1.90) \mathrm{p}<0.001 \\ 1.56(1.41,1.73) \mathrm{p}<0.001 & 1.48(1.30,1.67) \mathrm{p}<0.001 \\ 1.36(1.21,1.52) \mathrm{p}<0.001 & 1.28(1.11,1.47) \mathrm{p}=0.001 \\ 1.48(1.33,1.64) \mathrm{p}<0.001 & 1.49(1.32,1.70) \mathrm{p}<0.001 \\ 1.58(1.43,1.73) \mathrm{p}<0.001 & 1.56(1.38,1.76) \mathrm{p}<0.001 \\ 1.22(1.07,1.38) \mathrm{p}=0.002 & 1.16(1.00,1.35) \mathrm{p}=0.05\end{array}$

\section{Healthy dietary choice at $\mathbf{4 3}$} years $^{1}$

\footnotetext{
${ }^{1}$ Dietary choice representing frequency of breakfast, type of milk, type of bread and number of daily portions of fruit and vegetables (odds of greater than median total score,
} representing healthy choice) 
Table 6: Odds ratios and 95\% confidence intervals representing the effect of a 1 SD increase in childhood cognitive score on mid-life hypertension and obesity risk

\section{Hypertension at 53 years}

\author{
$0.86(0.79,0.94) \quad p<0.001$
}

$0.86(0.79,0.94) p=0.001$

$0.91(0.83,1.00) p=0.06$

$0.89(0.80,0.98) p=0.02$

$0.86(0.79,0.95) \quad p=0.002$

$0.95(0.85,1.07) p=0.43$
$0.91(0.82,1.02) \quad p=0.11$

Obesity (BMI $\geq 30 \mathrm{~kg} / \mathrm{m}^{2}$ ) at 53 years

\begin{tabular}{|c|c|c|c|c|c|c|}
\hline Unadjusted & $0.86(0.79,0.94)$ & $p<0.001$ & $0.82(0.74,0.90)$ & $p<0.001$ & $0.78(0.62,0.99)$ & $p=0.04$ \\
\hline Gender & $0.86(0.79,0.94)$ & $p=0.001$ & $0.82(0.74,0.90)$ & $p<0.001$ & $0.78(0.62,0.98)$ & $p=0.04$ \\
\hline Parental SES & $0.91(0.83,1.00)$ & $p=0.06$ & $0.90(0.81,1.00)$ & $p=0.06$ & $0.88(0.68,1.14)$ & $p=0.33$ \\
\hline Own education & $0.91(0.82,1.02)$ & $p=0.11$ & $0.95(0.84,1.08)$ & $p=0.41$ & $1.00(0.74,1.35)$ & $p=0.98$ \\
\hline Mid-life social class & $0.89(0.80,0.98)$ & $p=0.02$ & $0.88(0.79,0.98)$ & $p=0.02$ & $0.94(0.72,1.23)$ & $p=0.66$ \\
\hline Mid-life income & $0.86(0.79,0.95)$ & $p=0.002$ & $0.85(0.76,0.94)$ & $p=0.001$ & $0.94(0.73,1.19)$ & $p=0.59$ \\
\hline All & $0.95(0.85,1.07)$ & $p=0.43$ & $1.01(0.88,1.16)$ & $p=0.86$ & $1.14(0.83,1.57)$ & $p=0.41$ \\
\hline
\end{tabular}

Diabetes by age 53 years

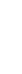

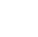

8


For all outcomes except hypertension, adjusting for education had the largest attenuating effect for a single covariate and this alone reduced associations for smoking, hypertension, obesity and diabetes to non-significance. Childhood SES had relatively little effect on the associations with health behaviours, but father's social class also reduced the associations with hypertension, obesity and diabetes to non-significance. The next most important covariate in this respect was mid-life social class, although income had relatively little attenuating effect, except on odds of diabetes. Associations between childhood cognition and abdominal circumference and waist-hip ratio, were similar to those for obesity (data not shown). The association between childhood cognition and obesity was not explained by the exercise or dietary choice outcome variables.

In the fully adjusted analyses, variables remaining in the models at the $5 \%$ significance level were educational attainment and mid-life social class and income for smoking and exercise; childhood cognition and education for healthy diet (with a stronger effect size for education); social class for hypertension and obesity (childhood and mid-life for the former, childhood only for the latter); and income only for diabetes.

For healthy diet, when percent total energy derived from fat was substituted for type of milk, results were broadly similar for all analyses, except that education attenuated the association to nonsignificance and that, for this reason, the association between childhood cognition and healthy diet was no longer significant in the fullyadjusted model.

\section{Discussion}

In this study we investigated cardiovascular risk factors as health returns to childhood cognitive capital in the 1946 birth cohort. This is a topic that has received increasing attention in recent years (see, for example, special edition, Intelligence 2009, volume 37 , number 6 ), although the precise relative contributions of cognition, education and socioeconomic attainment to long-term health outcomes are still a matter of controversy. We found that childhood cognition was significantly associated with six cardiovascular risk factors: lifetime smoking, mid-life physical exercise and dietary choice, mid-life hypertension and obesity and Type
2 diabetes up to mid-life. However, for all these outcomes except exercise and healthy diet, this association was mediated by education and SES, with education playing the stronger role in this respect. These results are broadly consistent with those from the British 1958 and 1970 cohorts (Chandola et al 2006; Batty et al 2007a, 2007b; Gale et al 2009; Power et al 2010).

We should highlight the disproportionate loss to follow-up in this cohort of those of lower cognitive ability in childhood; this limits the generalisability of our findings, although data imputation in a related study suggests that this would not have significantly altered the pattern or strength of these associations (Richards et al 2009). To set against this, the major strengths of this study are the national sampling frame, the large sample and the availability of prospective life course data.

With this in mind, how should the present results be interpreted? Childhood cognitive capital is an important determinant of education (Deary et al 2007), which in turn structures adult social position (Mirowsky and Ross 2003), with multiple consequences for health (Link and Phelan 2008). So while cognitive capital is demonstrably not a sufficient cause of long-term health variation, it might be argued that it is 'fundamental' (Gottfredson 2004), in that it 'sets in motion' this 'chain of events' (Chandola et al 2006) that drives health. Yet even this is only a partial truth. To begin with, the latter authors themselves note that the chain probably begins in early life (ibid) and while this raises the role of genetic influence, cognition is also at its most malleable at this stage of the life course (Deary et al 2009). Moving further along the chain, Chandola et al (2006) also note that education is capable of having an effect on health that is independent of childhood cognition. Indeed, education is capable of augmenting cognition itself, independently of prior ability (Snow and Yallow 1982; Hernstein and Murray 1994; Richards and Sacker 2003; Hatch et al 2007a). There are compelling reasons why education influences health independently of cognitive capital. Schooling teaches specific knowledge, teaches practical skills, refines other cognitive skills and shapes confidence, motivation and self-regulation (Kohn and Slomczynski 1993), all of which are important for self-management of health. This is not purely a matter of 'input' (Rutter 1985); as well as having a clear focus on academic goals and effective use of 
classroom management, teaching and motivational techniques, schools that successfully promote academic achievement tend to encourage student participation in and responsibility for, the running of school life (ibid). Education also provides a readily identifiable credential (Collins 1979), or signal (Rosenbaum et al 1990), that enables employers to select the individual into the workforce and onto an adult SES trajectory.

As noted, we found that social class of origin attenuated associations between childhood cognition and hypertension and obesity to nonsignificance and that these effects remained independent in the fully-adjusted models for these two outcomes. Such attenuating effects of childhood social class on associations between childhood cognition and these two outcomes were not found in the 1958 cohort (Power et al 2010), or the 1970 cohort (Batty et al 2007a). Further work is necessary to determine the reasons for this discrepancy. It may be, for example, that early childhood material home conditions in manual occupational households in the 1946 cohort, which were generally poorer than those in the early years of the 1958 and 1970 cohorts, had a greater longterm impact on health. In this context it should be noted that the 1946 cohort were born during a severe housing shortage, when overcrowding was common, only $57 \%$ of families in 1946 had their own bathroom and $51 \%$ had running hot water (Wadsworth 1991). Furthermore, serious childhood infectious diseases such as diphtheria, lobar pneumonia, poliomyelitis and whooping cough were more common in this cohort than in later years (ibid).

The two outcomes in this study where the association with childhood cognition was robust to the potential confounders, were healthy diet and physical exercise. Reasons for the former are unclear, although they are consistent with the findings of Gale et al (2007) for childhood cognition in relation to vegetarian diet. We should note that education had a strong mediating effect when percent total energy derived from fat was substituted for type of milk in the summary score, although this does not strictly represent dietary choice. Our finding for exercise is consistent with that of Batty et al (2007a) in the 1970 cohort for intense physical exercise. How may the latter apparent independent association be interpreted? From a health behaviour perspective, it is not immediately obvious why childhood intelligence would directly predict engagement in exercise but not avoidance of smoking. However, given the long-term stability of physical activity patterns (Kuh and Cooper 1991) and given the enhancement of neural growth processes by physical exercise (Cotman et al 2007), the possibility of reverse causation occurring relatively early on in the life course cannot be ruled out at this stage.

Even allowing these exceptions of diet and exercise, we do not argue that adult health returns to cognitive capital are all mediated by education and SES, or driven by early life influences, or indeed that cognitive capital only plays a minor role in determining health disparities. We have previously suggested that cognition is likely to exert its strongest influence when the health outcomes in question most closely reflect the functioning of the central nervous system (Richards et al 2009). Above all, this concerns risk of cognitive decline and dementia (Whalley et al 2006), since cognition itself strongly tracks across the life course (Deary et al 2000; Plassman et al 1995; Snowdon et al 1996), even when the influence of education and father's and own occupation are controlled (Richards and Sacker 2003); and it influences rate of cognitive decline (Richards et al 2004). In this context, independent associations were also observed in the British birth cohorts between cognitive capital and affective symptoms (Hatch et al 2007b; Gale et al 2009b), which involve many neural systems common to cognition. Cognition may also act uniquely as a marker for biological programming, as it almost certainly does in the case of natural menopause timing (Richards et al 1999), where not only is the association highly robust, but is stronger the earlier cognition is measured in childhood (ibid). On the other hand associations appear to be more readily explained by education and SES when the outcomes concern risk of chronic physical diseases in ageing. Further work is required to elucidate the detailed factors underlying this mediation, although it seems unlikely that another single 'fundamental cause' (such as health self-management or 'literacy') will be uncovered further downstream; more likely there will be an aggregate effect of schooling, occupational exposures, lifestyle, individual amenities and the macro-level influence of neighbourhood, all layered over the long-term impact of genetic and early life factors. We should be wary of simplification in other ways too; 
Richards et al (2005) found that childhood cognition had a robust independent association with FEV1, which predicts chronic lung disease; whereas associations with the more overt biomarker of cortisol activity were partly or wholly mediated by education (Power et al 2010). These findings will be important to revisit as the birth cohorts move towards later life.

\section{Acknowledgements}

The authors are all funded by the Medical Research Council. We are grateful to the Nuffield Foundation for funding the original seminar series on which this article was based.

\section{References}

Batty GD, Deary IJ, Schoon I and Gale CR. (2007a) Mental ability in relation to risk factors for premature mortality in adult life: the 1970 British Cohort Study. Journal of Epidemiology and Community Health, 61, 997-1003.

Batty GD, Deary IJ, Schoon I and Gale CR. (2007b) Childhood mental ability in relation to food intake and physical activity in adulthood: the 1970 British Cohort Study. Pediatrics, 119, e38-45.

Batty GD, Deary IJ, Schoon I, Emslie C, Hunt K and Gale CR. (2008) Childhood mental ability and adult alcohol intake and alcohol problems: the 1970 British cohort study. American Journal of Public Health, 98, 2237-2243.

Blane D. (2003) Explanations of the difference in mortality risk between different educational groups. International Journal of Epidemiology, 32, 355-356.

Chandola T, Deary IJ, Blane D and Batty GD. (2006) Childhood IQ in relation to obesity and weight gain in adult life: the National Child Developmental (1958) Study. International Journal of Obesity, 30, $1422-1432$.

Collins R. (1979) The credential society: an historical sociology of education and stratification. Academic Press, New York.

Cotman CW, Berchtold NC and Christie LA. (2007) Exercise builds brain health: key roles of growth factor cascades and inflammation. Trends In Neurosciences, 30, 464-472.

Deary IJ, Whalley LJ, Lemmon H, Crawford JR and Starr JM. (2000) The stability of individual differences in mental ability from childhood to old age: follow-up of the 1932 Scottish Mental Survey. Intelligence, 28, 49-55.

Deary IJ, Strand S, Smith P and Fernandes C. (2007) Intelligence and educational achievement. Intelligence, 35, 13-21.

Deary IJ, Johnson W and Houlihan LM. (2009) Genetic foundations of human intelligence. Human Genetics, 126, 215-232.

Duckworth K, Akerman R, MacGregor A, Salter E and Vorhaus J. (2009) Self-regulated learning: a literature review. www.learningbenefits.net/Publications/ResRepIntros/ResRep33intro.htm

Duckworth K and Schoon I. (2010) Progress and attainment during primary school. Longitudinal and Life Course Studies, 1, 223-240.

Elliott J and Shepherd P. (2006) Cohort profile: 1970 British Birth Cohort (BCS70) International Journal of Epidemiology, 35, 836-843.

Gale CR, Deary IJ, Schoon I and Batty GD. (2007) IQ in childhood and vegetarianism in adulthood: 1970 British cohort study. British Medical Journal 334 (7587), 245.

Gale CR, Johnson W, Deary IJ, Schoon I and Batty GD. (2009a) Intelligence in girls and their subsequent smoking behaviour as mothers: the 1958 National Child Development Study and the 1970 British Cohort Study. International Journal of Epidemiology, 38, 173-181.

Gale CR, Hatch SL, Batty GD and Deary IJ. (2009b) Intelligence in childhood and risk of psychological distress in adulthood: the 1958 National Child Development Survey and the 1970 British Cohort Study. Intelligence, 37, 592-599.

Gottfredson LS. (2004) Intelligence: is it the epidemiologists' elusive "fundamental cause" of social class inequalities in health? Journal of Personality and Social Psychology, 86, 174-199.

Hatch SL, Feinstein L, Link B, Wadsworth MEJ, Richards M. (2007a) Continuing benefits of education: adult education and mid-life cognitive ability in the British 1946 birth cohort. Journal of Gerontology Series B, 62, S404-S414. 
Hatch SL, Jones PB., Kuh D, Hardy R, Wadsworth MEJ and Richards M. (2007b) Childhood cognitive ability and adult mental health in the British 1946 birth cohort. Social Science and Medicine, 64, 22852296.

Hernstein RJ and Murray C. (1994) The bell curve: intelligence and class structure in American life. p 591, table, The Free Press, New York.

Jefferis BJ, Manor $\mathrm{O}$ and Power C. Cognitive development in childhood and drinking behaviour over two decades in adulthood. Journal of Epidemiology and Community Health, 62, 506-512.

Jokela M, Batty GD, Deary IJ, Gale CR and Kivimaki M. (2009) Low childhood IQ and early adult mortality: the role of explanatory factors in the 1958 British birth cohort. Pediatrics [epub ahead of print].

Kohn M and Slomcznski KM. (1993) Social structure and self-direction. A comparative analysis of the United States and Poland. Blackwell, Cambridge, MA.

Kuh D and Cooper C. (1991) Physical activity at 36 years: patterns and childhood predictors in a longitudinal study. Journal of Epidemiology and Community Health, 46, 114-119.

Kuh D, Richards M, Hardy R, Butterworth S and Wadsworth MEJ. (2004) Childhood cognitive ability and deaths up until middle age: a post-war birth cohort study. International Journal of Epidemiology, 33, 408-413.

Kuh D, Butterworth S, Kok H, Richards M, Hardy R, Wadsworth MEJ and Leon D. (2005) Childhood cognitive ability and age at menopause: evidence from two cohort studies. Menopause, 12, 475-82.

Kuh D, Shah I, Richards M, Mishra G, Wadsworth MEJ and Hardy R. (2009) Do childhood cognitive ability or smoking behaviour explain the influence of lifetime socio-economic conditions on premature adult mortality in a British post war birth cohort? Social Science and Medicine, 68, 1565-1573.

Langenberg C, Kuh D, Wadsworth MEJ, Brunner E and Hardy R. (2006) Social circumstances and education: life course origins of social inequalities in metabolic risk in a prospective national birth cohort. American Journal of Public Health, 96, 2216-2221.

Link BG and Phelan JC. (2008) The resources that matter: fundamental social causes of health disparities and the challenge of intelligence. Journal of Health and Social Behavior, 49, 367-84.

Mirowsky J and Ross CE. (2003) Education, social status and health. Aldine de Gruyter, New York.

O'Rand A. (2001) Stratification and the life course: the forms of life-course capital and their interrelationships. In RH Binstock and LK George. eds. Handbook of aging and the social sciences. pp 197-213. Academic Press, San Diego.

Office of Population Censuses and Surveys (1970) Classification of occupations. HMSO, London.

Plassman B, Welsh K, Helms M, Brandt J, Page W and Breitner J. (1995) Intelligence and education as predictors of cognitive state in late life: a 50-year follow-up. Neurology, 45, 1446-50.

Plomin R. (1999) Genetics and general cognitive ability. Nature, 402 (6761 Suppl.), C25-C29.

Power C and Elliott J. (2005) Cohort profile: 1958 British birth cohort (National Child Development Study) International Journal of Epidemiology, 35, 34-41.

Power C, Li L and Hertzman C. (2008) Cognitive development and cortisol patterns in mid-life: findings from a British birth cohort. Psychoneuroendocrinology, 33, 530-539.

Power C, Jefferis BJ and Manor O. (2010) Childhood cognition and risk factors for cardiovascular disease in mid-adulthood: the 1958 British birth cohort study. American Journal of Public Health, 100, 129136.

Price GM, Paul AA, Key FB, Harter AC, Cole TJ, Day KC et al. (1995) Measurement of diet in a large national survey: comparison of computerised and manual coding in household measures. Journal of Human Nutrition and Diet, 8, 417-428.

Prynne CJ, Paul AA, Mishra GD, Greenberg DC and Wadsworth MEJ. (2005) Changes in intake of key nutrients over 17 years during adult life of a British birth cohort. British Journal of Nutrition, 94, 368-376.

Richards M and Deary IJ (2010) Children and cognitive capital: an introduction. Longitudinal and Life Course Studies, 1,197-200.

Richards M, Kuh D, Hardy R and Wadsworth MEJ. (2009) Lifetime cognitive function and timing of the natural menopause. Neurology, 1999, 52, 308-14.

Richards M and Sacker A. (2003) Lifetime antecedents of cognitive reserve. Journal of Clinical and Experimental Neuropsychology, 25, 614-24.

Richards M, Hardy R and Wadsworth MEJ. (2003) Does active leisure protect cognition? Evidence from a national birth cohort. Social Science and Medicine, 56, 785-92.

Richards M, Shipley B, Fuhrer R and Wadsworth MEJ. (2004) Cognitive ability in childhood and cognitive decline in mid-life: longitudinal birth cohort study. British Medical Journal 328, 552-4.

Richards M, Strachan D, Hardy R, Kuh D and Wadsworth MEJ. (2005) Cognitive ability and lung function in a longitudinal birth cohort study. Psychosomatic Medicine, 67, 602-608.

Richards M, Black S, Mishra G, Gale C, Deary IJ and Batty GD. (2009) IQ in childhood and the metabolic syndrome in middle age: extended follow-up of the 1946 British birth cohort study. Intelligence, $37,567-572$. 
Rosenbaum JE, Kariya T, Settersen R and Maier T. (1990) Market and network theories of the transition from high school to work: their application to industrialized societies. Annual Review of Sociology, 16, 263-299

Ross CE and Mirowsky J. (1999) Refining the association between education and health: the effects of quantity, credential and selectivity. Demography, 36, 445-460.

Rutter M. (1985) Family and school influences on cognitive development. Journal of Child Psychology and Psychiatry, 26, 683-704.

Snow RE and Yalow E. (1982) Education and intelligence. In R. J. Sternberg ed. Handbook of human intelligence. Cambridge University Press, Cambridge.

Snowdon DA, Kemper SJ, Mortimer JA, Greiner LH, Wekstein DR and Markesbery WR. (1996) Linguistic ability in early life and cognitive function and Alzheimer's disease in late life. Findings from the Nun Study. Journal of the American Medical Association, 275, 528-32.

Wadsworth MEJ, Kuh D, Richards M and Hardy R. (2006) Cohort profile: the 1946 National Birth Cohort (MRC National Survey of Health and Development) International Journal of Epidemiology, 35, 49-54.

Whalley $\sqcup$ and Deary IJ (2001) Longitudinal cohort study of childhood IQ and survival up to age 76 . British Medical Journal 322, 1-5.

Whalley $\sqcup$, Dick FD and McNeill G. (2006) A life-course approach to the aetiology of late-onset dementias. Lancet Neurology, 5, 87-9.

\section{Endnotes}

'For a discussion of this term see Richards and Deary, this issue. 